\title{
SILICONE RESIN AND ELASTOMER PROTECTION OF HYBRID CIRCUITS
}

\author{
BRIAN R. TREGO \\ Dow Corning Limited, Barry, South Glamorgan, United Kingdom.
}

(Received April 4, 1979)

\begin{abstract}
Developments in encapsulants, in particular in relation to stress and humidity protection, are examined. Superior protection can now be achieved with flexible room temperature curing silicone encapsulants.
\end{abstract}

\section{INTRODUCTION}

Silicone resin and elastomeric polymers, filled and unfilled, are used to encapsulate hybrid circuits. The products are applied by a variety of potting, coating and moulding techniques. This paper examines developments in silicone encapsulants aimed at improving performance and circuit reliability. Two areas seen as critical have received special attention:

- Stress within the package

- Humidity protection

The mismatch in expansion between encapsulant and circuit components can lead to component failure and encapsulant cracking, especially where rigid encapsulants are employed. To try and overcome this problem most rigid encapsulants are highly filled.

Our approach has been to develop soft flexible room temperature curing silicone encapsulants in order to reduce mechanical and thermal stress on sensitive components. Examples of these sensitive components are bonded chips and temperature sensitive capacitors and resistors. One of the developed products, a potting compound, is a gel in the cured state. This is self healing but non flowing in the liquid sense. Two other developments are low viscosity coatings which have good adhesion to most metals and substrates.

Adhesion of the encapsulant can usually be related to device performance under humidity stress. However, encapsulant composition is also an important factor in humidity protection. Salts and other chemicals in the encapsulant will normally accelerate circuit failures. Many hybrid circuits utilise plastic encapsulated semi-conductors. It is important that the plastic provides good humidity protection. A new silicone-epoxy plastic moulding compound is described which combines the sealing performance associated with epoxy plastics and the high purity associated with silicone plastics. Performance of integrated circuits in this plastic is compared with a number of presently used plastics under autoclave and salt spray conditions.

\section{DISCUSSION}

Silicone developments for potting, coating and moulding circuits are described.

\subsection{Potting}

A large number of silicone elastomeric and epoxy resin products are used to pot circuits. In many cases fillers are incorporated to cheapen the product and reduce the expansion, the target being to bring the expansion of the encapsulant in line with the value of components on the circuit. Some expansion data on circuit materials, fillers and polymers are given in Table I.

Increasing the filler level in the encapsulant reduces its expansion coefficient. However, the limit to the filler addition is the need for the compound to be pourable. It is not possible to match the expansion of the encapsulant and circuit components. This mismatch can result in component failure on thermal cycling of encapsulated circuits, especially where rigid encapsulants with good adhesion are used. For example, in epoxy resin potting of thick film circuits with bonded chips, it is possible to damage chip and bond wires. 
TABLE I

Linear coefficient of expansion $\left(\mathrm{cm} / \mathrm{cm} /{ }^{\circ} \mathrm{C} \times 10^{6}\right)$ of some circuit materials, fillers and polymers

\begin{tabular}{lc}
\hline Unfilled Polymers & $100-350$ \\
Unfilled Flexible Sylgard ${ }^{\circledR} 182$ & 320 \\
Aluminium & 25 \\
Copper & 17 \\
Fused Silica Filler & 0.5 \\
Quartz Silica Filler & 10 \\
Alumina Substrate & 6 \\
\hline
\end{tabular}

Silicone elastomeric potting compounds (e.g. Sylgard $^{\circledR} 182$ ) have the advantage over epoxy compounds of flexibility but adhesion can be a problem. A lower modulus encapsulant with good circuit adhesion properties was desirable. We believe these parameters have been met with Q3-6527 which cures to a soft, slightly tacky, gel at room temperature. Its tacky nature and low modulus ensures its adhesion to virtually any substrate and prevents catastrophic adhesive failure at the bond face on thermal shock cycling.

We compared the corrosion protection afforded to mild steel by the gel and two commercially available types of room temperature curing silicone encapsulants. Films $2 \mathrm{~mm}$ thick were coated and cured onto the steel which was then subjected to a cycle at $25^{\circ} \mathrm{C}$ of $100 \% \mathrm{RH}$ for 30 minutes followed by 30 minutes drying. The results in Table II show the superior performance of the gel.

TABLE II

Comparison of the corrosion rate of mild steel protected with silicone gel and 2 elastomeric silicone encapsulants

\begin{tabular}{lllc}
\hline Encapsulant & Compound Type & Primer & $\begin{array}{l}\text { No. of Cycles } \\
\text { to Corrosion }\end{array}$ \\
\hline None & - & - & 2 \\
Sylgard $^{\circledR} 182$ & Unfilled Potting $^{\circledR}$ & No & 45 \\
Sylgard $^{\circledR} 182$ & Unfilled Potting & Yes & $>1000$ \\
3140 & Filled Coating & No & 750 \\
3140 & Filled Coating & Yes & $>1000$ \\
Q3-6527 Gel & Unfilled Potting & No & $>1000$ \\
\hline
\end{tabular}

\subsection{Coating}

The demands on coating materials in the electricalelectronic industries increase each year. It used to be the aerospace industry which needed encapsulated circuits to withstand severe stress and yet be as light as possible. Now the demand from the car industry grows for coatings which will withstand temperatures as high as $200^{\circ} \mathrm{C}$, severe thermal shock and humid conditions.

Many of the existing silicone, epoxy and polyurethane coatings will not meet these needs. This is not surprising since the products were often developed for alternative uses such as silicone adhesives, resistor cements etc. Two new products have been developed specially for thick films and printed circuit board circuits. These are low viscosity room temperature curing silicone products with excellent adhesion to most substrates.

\subsubsection{Q3-6550. This is a filled dispersion coating which cures to a soft elastomer (Shore A of 20 ) by reacting with moisture. Its low viscosity ensures excellent wetting of substrate and components and penetration under chips and bonding. Jaffe has evaluated this coating on thick film circuits consisting of tantalum thin film passive components and beam lead integrated circuits. ${ }^{1}$ He reports excellent penetration of the coating under the integrated circuit and humidity protection (Table III).}

\subsubsection{R-4-3117. For many hybrid circuits,} especially printed circuit boards, a coating which cures to a glossy tough surface is needed. However, it should also exhibit elastic properties if stress relief is to be achieved. R-4-3117, an unfilled polymer solution, meets these demands. The cured coating is hard (Shore A of 70) but also exhibits excellent elongation (more than 30\%). This elongation is independent of temperature over a wide temperature range, resulting in a coating which has excellent thermal shock resistance, to as low as $-70^{\circ} \mathrm{C}$.

The excellent protection of circuits observed can

TABLE III

Protection of thick film hybrid circuits by Q3-6550

\begin{tabular}{lll}
\hline Test Conditions & Components & Result \\
\hline $85^{\circ} \mathrm{C} / 85 \mathrm{RH} / 180 \mathrm{~V}$ bias & Tantalum resistors & Best silicone tested \\
$85^{\circ} \mathrm{C} / 85 \mathrm{RH} / 1000 \mathrm{~h} / \mathrm{bias}$ & Bipolar beam lead IC's & No failures \\
$-40^{\circ} \mathrm{C}$ to $150^{\circ} \mathrm{C} / 50$ cycles & Bipolar beam lead IC's & No failures \\
\hline
\end{tabular}


TABLE IV

Comparison of R-4-3117 with epoxy and urethane coatings

\begin{tabular}{|c|c|c|}
\hline Coating & Test & Result \\
\hline$R-4-3117$ & VL QMFZ-2† & $\begin{array}{l}\text { Recognised } 8 \text { to } 14,000 \mathrm{~V} \\
\text { breakdown }\end{array}$ \\
\hline $\mathrm{R}-4-3117$ & 24 hrs water abs. & $0 \%$ pick up \\
\hline Typical epoxy/urethane & $24 \mathrm{hrs}$ water abs. & $0.25 \%$ pick up \\
\hline$R-4-3117$ & $\begin{array}{l}\text { Water vapour } \\
\text { transmission } \ddagger\end{array}$ & $0.0034 \mathrm{gm} / \mathrm{cm}^{2} / \mathrm{cm}$ \\
\hline Typical epoxy/urethane & $\begin{array}{l}\text { Water vapour } \\
\text { transmission } \ddagger\end{array}$ & $0.006 \mathrm{gm} / \mathrm{cm}^{2} / \mathrm{cm}$ \\
\hline$R-4-3117$ & $\begin{array}{l}\text { Volume resistivity } \\
\text { R.T. and }\left(100^{\circ} \mathrm{C}\right)\end{array}$ & $9 \times 10^{14}\left(5 \times 10^{14}\right) \mathrm{ohm} \mathrm{cm}$ \\
\hline Typical epoxy/urethane & $\begin{array}{l}\text { Volume resistivity } \\
\text { R.T. and }\left(100^{\circ} \mathrm{C}\right)\end{array}$ & $1 \times 10^{15}\left(1 \times 10^{10}\right) \mathrm{ohm} \mathrm{cm}$ \\
\hline
\end{tabular}

$\dagger$ Underwriters Laboratory humidity testing of coated circuit boards. \$ASTM D-1653.

be related to:

- the good adhesion to most components and substrates,

- the very low water pick up and permeability and

- the electrical properties of the product.

Data on these parameters and comparison with some epoxy and urethane coatings is given in Table IV.

\subsection{Moulding}

Component temperature stability and stress problems have made moulding of thick film hybrids an unattractive process. However, dual encapsulating techniques are common. For example, silicon chips moulded in plastic are bonded onto thick film substrates and the circuit potted. The reliability of these hybrid circuits is dependent on the plastic used. To date the preferred moulding compounds have been epoxy and silicone resin based. Epoxies give good sealing but are inferior to silicones on purity and handling ease. There was a need for a plastic with the good properties of both. This has been achieved with the recently introduced silicone epoxy plastic. Autoclave and salt spray findings on integrated circuits, encapsulated in epoxy, silicone and the silicone epoxy plastic support this statement. These findings are described below.

2.3.1. Autoclave. Autoclave testing of encapsulated circuits is a common test method for determining encapsulant purity and sealing. Corrosion of aluminium pads, tracks and connections occurs by a number of steps in the presence of plastic contaminants resulting in electrical parameter changes or open circuits. Aluminium is normally protected by an oxide film but in the presence of certain salts this can be destroyed leaving the metal open to attack by acids and bases from the plastic. It is difficult to produce epoxy plastics free of alkali and chloride ions and anhydrides or amines are used as catalysts. In contrast, silicone plastics can be produced with a very low level of alkali and chloride ions and acids and bases are not used to cure the silicone resins. This superior purity is reflected in the autoclave findings on plastic encapsulated 4011 CMOS circuits (Table V). In this study CMOS circuits from the same wafer were encapsulated in 3 commercial epoxy novalac plastics (Table V, No's 1 to 3 ), a silicone and the silicone epoxy. The silicone performs best, closely followed by the silicone-epoxy. To confirm the epoxy failure rates are of the right order of magnitude we purchased epoxy encapsulated 4011 CMOS

TABLE V

Autoclave testing of plastic encapsulated 4011 CMOS circuits

\begin{tabular}{lcl}
\hline Plastic & $\begin{array}{l}\text { Time to 10\% } \\
\text { Failure (hrs) }\end{array}$ & $\begin{array}{l}\text { Time to 40\% } \\
\text { Failure (hrs) }\end{array}$ \\
\hline Silicone & $>400$ & - \\
Silicone-Epoxy & 400 & - \\
Epoxy 1 & 100 & 125 \\
Epoxy 2 & 185 & 210 \\
Epoxy 3 & 225 & 375 \\
& & \\
Epoxy A & 90 & 150 \\
Epoxy B & 100 & 180 \\
Epoxy C & 150 & 190 \\
Epoxy D & 200 & 275 \\
\hline
\end{tabular}


TABLE VI

Salt spray testing of plastic encapsulated 7400 TTL circuits (\% failure)

\begin{tabular}{lcccc}
\hline Condition & $\begin{array}{l}\text { Salt Spray } \\
(\mathrm{hrs})\end{array}$ & Silicone & Epoxy & $\begin{array}{l}\text { Silicone- } \\
\text { Epoxy }\end{array}$ \\
\hline Unaged & 50 & 20 & 0 & 0 \\
Unaged & 200 & 100 & 0 & 0 \\
Aged $1000 \mathrm{~h} / 125^{\circ} \mathrm{C}$ & 150 & 100 & 15 & 0 \\
Aged $1000 \mathrm{~h} / 125^{\circ} \mathrm{C}$ & 250 & 100 & 30 & 0 \\
Aged $1000 \mathrm{~h} / 175^{\circ} \mathrm{C}$ & 50 & 100 & 60 & 0 \\
Aged $1000 \mathrm{~h} / 175^{\circ} \mathrm{C}$ & 100 & 100 & 100 & 0 \\
Aged $1000 \mathrm{~h} / 175^{\circ} \mathrm{C}$ & 200 & 100 & 100 & 30 \\
\hline
\end{tabular}

circuits from 4 suppliers and subjected these to the same treatment (see Table V, A to D results). More detailed autoclave and salt spray findings on TTL and CMOS circuits in the 3 types of plastic have been reported. $^{2}$

\subsubsection{Salt Spray. We have considered the role} played by the plastic composition on device performance. Degradation can also be caused by external agents such as tin plating, salt spray and industrial gases. To determine the protection afforded by the plastic, salt spray testing has become common.

We subjected one wafer fabrication lot of 7400 TTL circuits, encapsulated in 3 types of plastic, to this test. Encapsulated devices were tested before and after ageing at $125^{\circ} \mathrm{C}$ and $175^{\circ} \mathrm{C}$. The findings (Table VI) confirm the poor protection provided by the silicone and reveal the superior performance of the silicone-epoxy over the epoxy. Ageing followed by salt spray testing or other humidity performance evaluating techniques could become an important method for measuring reliability.

\section{CONCLUSION}

The low purity and high modulus of many encapsulation compounds can be a problem when coating or potting thick film circuits. High purity junction coatings are often necessary on sensitive chips to act as a barrier to moisture and metal degradants from the encapsulant. ${ }^{3}$ One application method is to bond a small rubber ring around the chip and wires and fill this with an elastomeric junction coating.

Trials described here and those being conducted at several companies indicate superior circuit protection is achievable with recently developed flexible room temperature curing silicone encapsulants.

\section{REFERENCES}

1. D. Jaffe, Encapsulation of Integrated Circuits Containing Beam Leaded Devices with a Silicone RTV Dispersion. Elec. Comp. Conf. Nov 1976.

2. R. C. Antonen, K. W. Michael, and J. H. Engelman, New Hybrid Electronic Moulding Compounds. J. Electron. Mater. 6, 1, 1977..

3. A. Rydin, Reliability of Plastic Encapsulated Hybrid Circuits. New Electron March 22nd 1977, p. 83-88. 

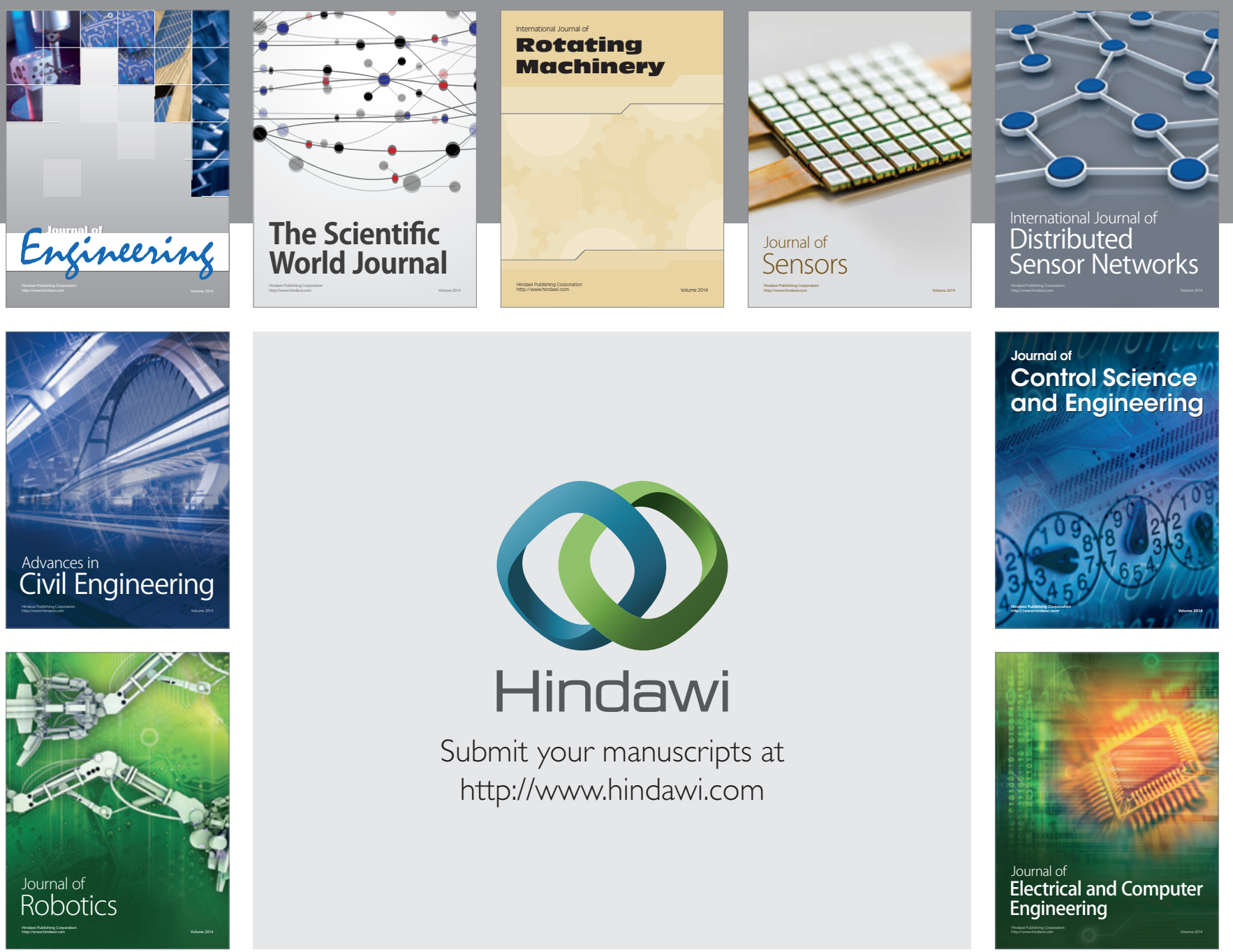

Submit your manuscripts at

http://www.hindawi.com
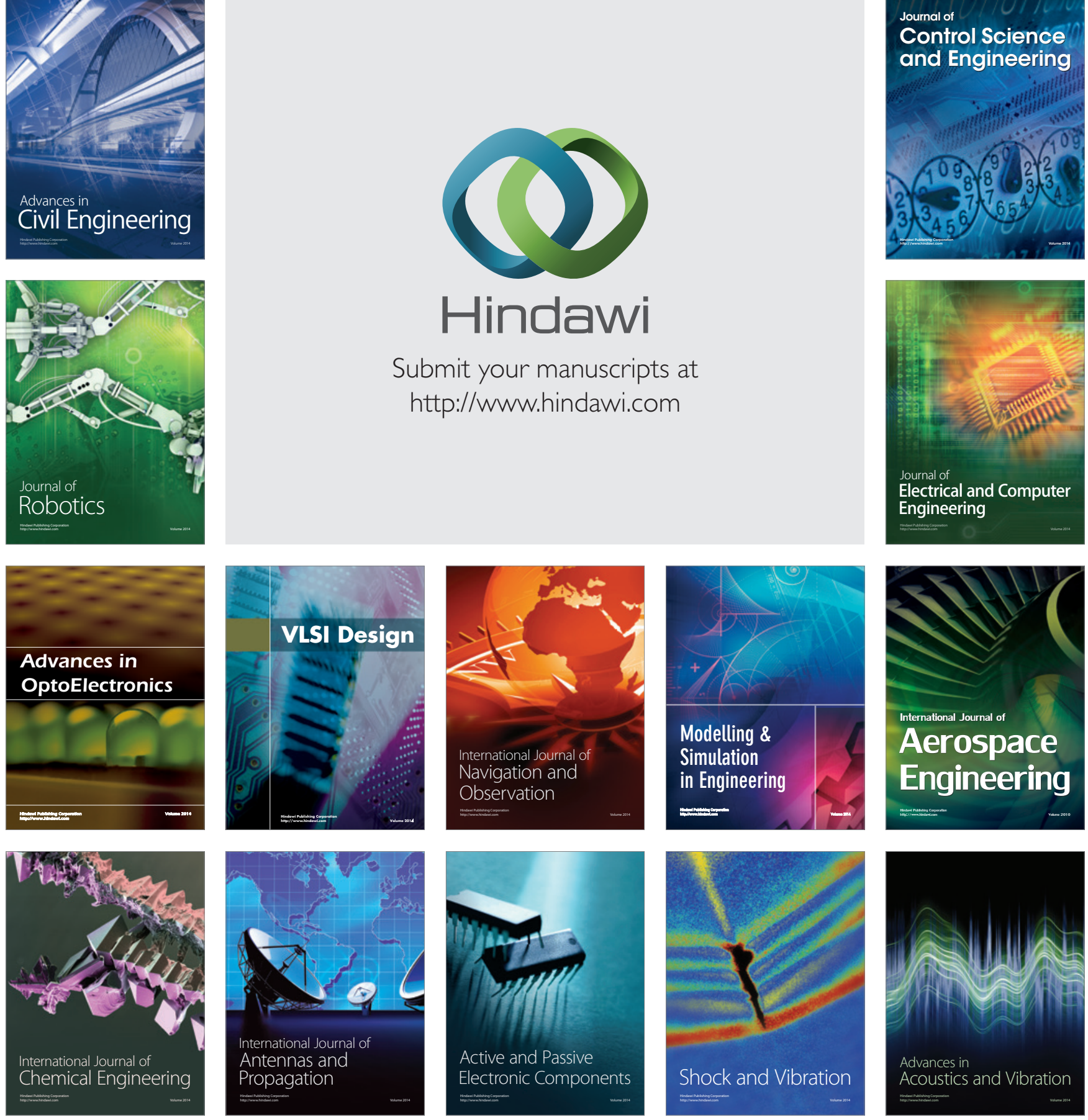